Communication

\title{
Calorimetric and Computational Study of Enthalpy of Formation of Diperoxide of Cyclohexanone
}

\author{
Jorge Marcelo Romero ${ }^{1}$, Soledad Bustillo ${ }^{1}$, Hugo Enrique Ramirez Maisuls ${ }^{1}$, \\ Nelly Lidia Jorge ${ }^{1}$, Manuel Eduardo Gómez Vara ${ }^{1}$, Eduardo Alberto Castro ${ }^{2, *}$ \\ and Alicia H. Jubert ${ }^{3}$
}

1 Área de Fisicoquímica, Facultad de Ciencias Exactas, Naturales y Agrimensura, Universidad Nacional del Nordeste, Corrientes, Argentina; E-mail: lidianj@exa.unne.edu.ar

2 INIFTA, Theoretical Chemistry Division, Suc. 4, C.C. 16, La Plata 1900, Buenos Aires, Argentina;

E-mail: castro@quimica.unlp.edu.ar; direccion@inifta.unlp.edu.ar

3 CEQUINOR, Chemistry Department, Faculty of Exact Sciences and Engineering Faculty, La Plata National University, C.C. 962, La Plata 1900, Buenos Aires, Argentina

* Author to whom correspondence should be addressed; E-mail: castro@quimica.inlp.edu.ar; direccion@inifta.unlp.edu.ar

Received: 27 February 200; in revised form: 18 July 2007 / Accepted: 18 July 2007 /

Published: 19 July 2007

\begin{abstract}
A thermochemical rather simple experimental technique is applied to determine the enthalpy of formation of Diperoxide of ciclohexanone. The study is complemented with suitable theoretical calculations at the semiempirical and $a b$ initio levels. A particular satisfactory agreement between both ways is found for the ab initio calculation at the 6$311 \mathrm{G}$ basis This set level. Some possible extensions of the present procedure are pointed out.
\end{abstract}

Keywords: tetroxane, diperoxide, enthalpy of formation, heat.

\section{Introduction}

Ketone and aldehyde diperoxides (1,2,4,5-tetroxanes) contain two peroxy groups in a six membered heterocycle and they are readily formed by acid-catalyzed oxidation of carbonyl compounds with 
hydrogen peroxide. Carbonyl oxide dimers are also used to describe these compounds since they can be generated by dimerization of a carbonyl oxide intermediate derived from ozonolysis of olefins [1-3].

Thermolysis of tetroxanes derived from cycloalkanones finds industrial use in the production of macrocyclic hydrocarbons and lactones [4-6]. Tetroxanes are capable of initiating polymerization of olefins and their utility as high temperature initiators is under examination [7]. More recently, tetroxanes have been found to posses an impressive antimalarial activity [8]. As a result of an apparent association between the peroxide functional group and antimalarial activity, a substantial effort has been devoted to developing new peroxide antimalarials [8-10].

In this article, we report the experimental determination of the enthalpy of formation of the diperoxide of ciclohexanone (DPCH) (Figure 1), since this compound posses antimalarial activity, as well as the theoretical results calculated from semiempirical and ab-initio Hartree-Fock methods.

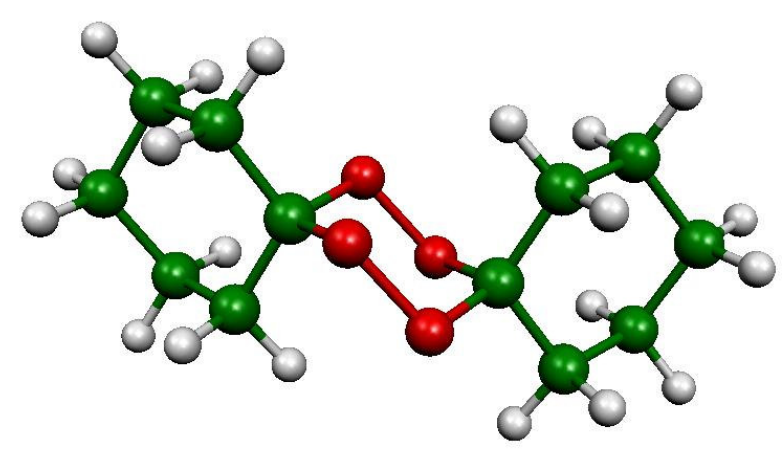

Figure 1. Structure of DPCH.

\section{Results and Discussion}

\subsection{Experimental enthalpy of formation}

Table 1 gives the results for a typical combustion experiment on compound DPCH. Table 2 gives the standard molar energy and enthalpy of combustion and formation of diperoxide of ciclohexanone, in the crystalline state at $\mathrm{T}=298.15 \mathrm{~K}$, and it corresponds to the chemical reaction:

$$
\mathrm{C}_{12} \mathrm{H}_{20} \mathrm{O}_{4}(c)+15 \mathrm{O}_{2}(g) \rightarrow 12 \mathrm{CO}_{2}(g)+10 \mathrm{H}_{2} \mathrm{O}(l)
$$

The uncertainties of the standard molar energy is four times the final overall standard deviation of the mean and they were estimated as outlined by statistical methods. Vapor pressure was determined at different temperatures and the enthalpy of sublimation was calculated as pointed out before.

The standard molar enthalpies of formation for both crystalline and gaseous states of the DPCH at $\mathrm{T}=298.15 \mathrm{~K}$ are also given in Table 2 . No combustion enthalpy and enthalpy of sublimation have been found in the standard literature for comparison purposes. 
Table 1. Results from typical combustion experiments at $298.15 \mathrm{~K}$.

\begin{tabular}{|c|c|c|c|c|c|c|c|c|}
\hline & 1 & 2 & 3 & 4 & 5 & 6 & 7 & 8 \\
\hline $\mathbf{M}_{\mathrm{DPCH}} / \mathrm{g}$ & 0.0008 & 0.0005 & 0.0010 & 0.0026 & 0.0016 & 0.0006 & 0.0007 & 0.0011 \\
\hline $\mathbf{m}_{\text {gel }} / \mathbf{g}$ & 0.0383 & 0.0405 & 0.0391 & 0.0363 & 0.0385 & 0.0385 & 0.0414 & 0.0414 \\
\hline $\mathbf{m}_{\mathrm{Fe}} / \mathrm{g}$ & 0.0092 & 0.0093 & 0.0096 & 0.0083 & 0.0087 & 0.0075 & 0.0112 & 0.0176 \\
\hline$\Delta \mathbf{T} / \mathbf{K}$ & 0.05620 & 0.056515 & 0.05604 & 0.05514 & 0.05599 & 0.05315 & 0.05923 & 0.06408 \\
\hline \multicolumn{9}{|l|}{$\left(m_{\text {water }}+\mathbf{E}\right) \Delta T / J$} \\
\hline $\mathbf{a}$ & 809.1952 & 840.8873 & 833.7457 & 820.4288 & 833.1059 & 790.7455 & 881.2692 & 953.4474 \\
\hline $\mathbf{m}_{\text {gel }} \Delta \mathbf{U}_{\text {gel }} / \mathbf{J}^{\mathbf{b}}$ & 698.4167 & 738.5346 & 713.0051 & 661.9456 & 702.0635 & 702.0635 & 754.9463 & 754.9463 \\
\hline $\mathbf{m}_{\mathrm{Fe}} \Delta \mathbf{U}_{\mathrm{Fe}} / \mathbf{J}^{\mathbf{c}}$ & 85.8389 & 86.7720 & 89.5711 & 77.4417 & 81.1738 & 69.9774 & 104.4996 & 164.2136 \\
\hline$\Delta \mathbf{U}_{\mathrm{c}} / \mathbf{J} / \mathbf{g}^{\mathbf{d}}$ & 31174.641 & 31162.118 & 31169.624 & 31169.808 & 31167.729 & 31173.660 & 31176.03 & 31170.256 \\
\hline$\Delta \mathbf{H}_{\mathrm{c}} / \mathbf{k J} / \mathbf{m o l}$ & -7115.27 & -7112.38 & -7114.10 & -7114.14 & -7113.68 & -7115.02 & -7115.56 & -7114.26 \\
\hline \multicolumn{9}{|c|}{${ }^{\mathrm{a}} \mathrm{m}_{\text {water }}=2700 \mathrm{~g}$} \\
\hline \multicolumn{9}{|c|}{${ }^{\mathrm{b}} \Delta \mathrm{U}_{\text {gel }}$ (heat of combustion of gelatine capsules) $=18235.13 \pm 2.72$ joule $/ \mathrm{g}$} \\
\hline \multicolumn{9}{|c|}{${ }^{\mathrm{c}} \Delta \mathrm{U}_{\mathrm{Fe}}($ heat of combustion of iron wire $)=9330.32 \pm 2.93$ joule $/ \mathrm{g}$} \\
\hline
\end{tabular}

\subsection{Theoretical calculation of the enthalpy of formation}

In the case of the diperoxide of ciclohexanone, the suitable isodesmic chemical reaction, is:

$$
2 \mathrm{CH}_{3}-\mathrm{O}-\mathrm{O}-\mathrm{CH}_{3}(\mathrm{DMP})(\mathrm{g})+2 \mathrm{C}_{6} \mathrm{H}_{12}(\mathrm{CH})(\mathrm{g}) \rightarrow \mathrm{DPCH}(\mathrm{g})+4 \mathrm{CH}_{4}(\mathrm{~g})
$$

The calculation were computed at the semiempirical, $a b$ initio and Functional Density Theory (DFT), with corrections for zero-point energies and differences in $H^{\circ} 298-H^{\circ} 0$.

In order to calculate enthalpy values at $298 \mathrm{~K}$, the difference between the enthalpy at temperature $\mathrm{T}$ and $0 \mathrm{~K}$ can be evaluated according to standard thermodynamics. The sum of electronic and enthalpies energies at $298 \mathrm{~K}$ at the Hartree Fock level using the semiempirical, ab initio and Functional Density Theory (DFT) procedures with different basis sets for the studied compounds, are also collected in Table 3. We have resorted to the semiempirical calculations at the AM1 and PM3 levels since it is well know that in these procedures a suitable adjustment of the elements of the F matrix is used to bring the calculated results into the best possible agreement with standard thermochemical results, largely enthalpy of formation [11]. Semiempirical methods like AM1 [12] and PM3 [13-15] provide a quite effective compromise between the accuracy of the results and the expense of computer time required. A calculation performed with AM1 and PM3 is able to reflect the experiment as effectively as an $a b$ initio calculation using a small basis set [16].

The heats of formation calculated through isodesmic reaction (2) are given in Table 4. The analysis 
of theoretical results show that ab initio procedures yield better results than semiempirical methods. Besides, the best agreement am among experimental data and theoretical predictions happens for the 3$21 \mathrm{G}$ basis set.

Table 2. Summary of experimental specific heats of combustion and standard molar thermodynamic function of DPCH at $\mathrm{T}=298.15 \mathrm{~K}$.

\begin{tabular}{l|c|c|c|c}
\hline & $\Delta U_{c}^{0}(\mathbf{c})^{\mathbf{a}}$ & $\begin{array}{c}-\Delta H_{c}^{0}(\mathbf{c})^{\mathbf{b}} \\
\mathbf{k J} / \mathbf{m o l}\end{array}$ & $\begin{array}{c}-\Delta H_{f}^{0}(\mathbf{c})^{\mathbf{c}} \\
\mathbf{k J} \mathbf{J} / \mathbf{m o l}\end{array}$ & $\begin{array}{c}-\Delta H_{f}^{0}(\mathbf{g})^{\mathbf{d}} \\
\mathbf{k J J} / \mathbf{m o l}\end{array}$ \\
\hline 1 & $\mathbf{j o u l e} / \mathbf{m o l}$ & -7115.27 & -465.18 & -402.84 \\
2 & 31174.641 & -7112.38 & -468.02 & -405.68 \\
3 & 31162.118 & -7114.10 & -466.31 & -403.97 \\
4 & 31169.624 & -7114.14 & -466.26 & -403.93 \\
5 & 31169.808 & -7113.68 & -466.73 & -404.38 \\
6 & 31167.729 & -7115.02 & -465.39 & -403.04 \\
7 & 31173.660 & -7115.56 & -464.84 & -402.50 \\
8 & 31176.030 & -7114.26 & -466.18 & -403.84 \\
\hline \multicolumn{1}{c|}{ Average } & 31170.256 & & & \\
$\quad$ value & 31170.483 & -7114.31 & -466.10 & -403.76 \\
\hline Standard & & & & \\
deviation & 1.057055 & 0.241008 & 0.241008 & 0.241008 \\
\hline
\end{tabular}

${ }^{\mathrm{a}}$ Standard molar heat of combustion

${ }^{\mathrm{b}}$ Standard enthalpy of combustion

${ }^{c}$ Standard enthalpy of formation in crystalline state

${ }^{\mathrm{d}}$ Standard enthalpy of formation in gas phase obtained from the sublimation molar enthalpy $\left(\Delta \mathrm{H}_{\mathrm{S}}=62.3 \mathrm{~kJ} / \mathrm{mol}\right)$

Table 3. Calculated electronic energy and heat of reaction (in Hartree units).

\begin{tabular}{lcccccc}
\hline \multicolumn{7}{c}{$-\left(\varepsilon_{0}+H_{\text {corr }}\right)^{a}[\mathbf{k J} / \mathbf{m o l}]$} \\
\hline & AM1 & PM3 & RHF & RHF & B3LYP & B3LYP \\
& & & $3-21 \mathrm{G}$ & $6-31 \mathrm{G}$ & $3-21 \mathrm{G}$ & $6-31 \mathrm{G}$ \\
\hline $\mathrm{DPCH}$ & -560.73 & -524.10 & 1997480.21 & 2007620.97 & 2010027.54 & 2020385.03 \\
$\mathrm{CH}_{4}$ & -89.49 & -74.38 & 104823.31 & 105358.23 & 105682.13 & 106231.30 \\
$\mathrm{CH}$ & -307.08 & -325.32 & 611026.75 & 614161.77 & 615492.77 & 618683.31 \\
$\mathrm{CH}_{3} \mathrm{OOCH}_{3}$ & -128.30 & -85.63 & 597260.18 & 600286.20 & 600769.65 & 603880.54 \\
$\Delta \mathrm{Hr}^{\mathrm{b}}$ & -47.91 & 0.28355 & 201.83 & 157.97 & 231.20 & 182.54 \\
\hline
\end{tabular}

${ }^{\mathrm{a}}$ Sum of electronic and thermal enthalpies at semiempirical and Hartree Fock ab initio techniques with different basis sets levels;

${ }^{\mathrm{b}}$ Heat of reaction obtained with semiempirical and Hartree Fock $a b$ initio techniques at different basis sets levels: $\Delta H_{r}=\sum\left(\varepsilon_{0}+H_{\text {corr }}\right)_{\text {products }}-\sum\left(\varepsilon_{0}+H_{\text {corr }}\right)_{\text {reac } \tan t s}$ 
Table 4. Enthalpy of formation of DPCH.

\begin{tabular}{ccc|c|c|c}
\hline \multicolumn{7}{c}{$\Delta H_{f}^{0}(g)^{a}\left[\mathbf{k J ~ m o l}{ }^{-1}\right]$} \\
\hline \multirow{2}{*}{ AM1 } & PM3 & $\begin{array}{c}\text { RHF } \\
3-21 G\end{array}$ & $\begin{array}{c}\text { RHF } \\
6-31 G\end{array}$ & $\begin{array}{c}\text { B3LYP } \\
3-21 G\end{array}$ & $\begin{array}{c}\text { B3LYP } \\
6-31 G\end{array}$ \\
\hline \multirow{2}{*}{-170.280} & -200.20 & -402.30 & -358.17 & -431.40 & -382.74 \\
\hline
\end{tabular}

${ }^{a}$ Standard enthalpy of formation in gas phase at the Hartree Fock $a b$ initio technique levels and with different basis set.

\section{Experimental Section}

\subsection{Material}

Diperoxide of ciclohexanone (DPCH) was prepared and purified as described elsewhere [17].

\subsection{Thermochemical measurements}

The measurement of the heat of combustion of diperoxide of ciclohexanone was made with an isoperibol macrocalorimeter fitted with a stirred water bath. The substance was burned in oxygen at $\mathrm{p}=$ $25 \mathrm{~atm}$.. The current of ignition was determined to be 2 Amp. The heat capacity of the calorimeter (E) was determined with a standard reference sample of benzoic acid (Sample SRM 39i, NIST) for all experiments. E was measured to be $(856.17 \pm 1.5) \mathrm{cal} / \mathrm{K}$. The crystalline compounds were pressed into gelatine capsules of masses $\approx 1 \times 10^{-3} \mathrm{~g}$. The reduction of the data to standard conditions was made through conventional procedures [18]. The atomic weights used were those recommended by the IUPAC Commission [19,20].

The vapor pressures as a function of temperature of DPCH were measured by a mercury manometer through a Bodestein differential equipment and the enthalpy of sublimation was deduced from the temperature dependence of the vapor pressures (Clausius-Clapeyron equation).

\subsection{Theoretical calculations}

Among the most important purposes of the calorimetric studies is to find out the molecular energy of a set of structurally and functionally related molecules in order to establish the corresponding structure-activity relationships and to be able to discuss the main electronic features determining the chemical reactivity.

It is well known that in order to make theoretical calculations of molecular enthalpy of formation it is necessary to find suitable isodesmic chemical reactions to optimize the corresponding molecular structure and to perform the frequency calculations from the optimized equilibrium molecular geometries applying the corresponding theoretical method to obtain the total electronic energy at 298 
K. Here we have chosen the Gaussian 94 package [21] to perform the theoretical calculations at the semiempirical and $a b$ initio levels.

When one tries to get the equilibrium molecular geometries, it is necessary to localize the absolute minimum at the potential energy hypersurface, which is not a trivial task. The optimization procedure is complete when the numerical process converges, i.e. when the forces are null and all the vibrational frequencies are real.

\section{Conclusions}

We have reported a rather simple and accurate enough experimental method to determine the enthalpy of formation of the title compound and we have complemented it with the theoretical calculation of the property under study via semiempirical, ab initio Molecular Orbital methods and DFT procedures. The theoretical value of the enthalpy of formation of diperoxide of ciclohexanone, $95.52 \mathrm{kcal} \mathrm{mol}^{-1}$, evaluated at the Hartree Fock at the 3-21 G basis set level, is in very good agreement with the experimental value, $-96.50 \mathrm{kcal} \mathrm{mol}^{-1}$. This methodology consisting in the experimental determination of the thermochemical property and its complementation with theoretical procedures represents a quite sensible way to study similar oxane derivatives molecules and at present further studies along this line are under development.

\section{Acknowledgements}

AHJ is member of the Research Career CIC and EAC is member of the Research Career CONICET.

\section{References and Notes}

1. a)McCullough, K.J.; Morgan, A.R.; Nonhebel, D.C.; Pauson, P.L.; White, G.J. Ketones-derived Peroxides. Part. III. Decompositions of Cyclic Peroxides derived from Dialkyl Ketones. J. Chem. Res. Synop. 1980, 2, 36-38, M0601. b)McCullough, K.J.; Morgan, A.R.; Nonhebel, D.C.; Pauson, P.L., Ketones-derived Peroxides. Part. I. Synthetic Methods. J. Chem. Res. Synop. 1981, 2, 34-36.

2. Leiva, L.C.A.; Romero, J.M.; Jorge, N.L.; Gómez Vara, M.E.; Cafferata, L.F.R. Síntesis y Descomposición Térmica Del Diperóxido De Formaldehído. Revista Internacional Información Tecnológica. 2002, 13(2), 23-26.

3. Adam, W.; Hadjiarapoglou, L.P.; Curci, R.; Mello, R. In Organic Peroxides; Ando, W., Ed.; John Wiley \& Sons: Chichester, England, 1992; Chapter 4.

4. Story, P.R.; Busch, P. In Advances in Organic Chemistry, Taylor, E.C. Ed.; Wiley: New York, 1972; Vol. 8, pp. 67-95.

5. Eyler G.N.; Mateo, C.M.; Alvarez, E.E.; Cañizo, A.I. Termal Decomposition reaction of Acetone Triperoxide in Toluene solution. J. Org. Chem. 2000, 65, 2319-2321.

6. Eyler G.N.; Mateo, C.M.; Álvarez, E.E.; Cañizo, A.I.; Cafferata, L.F.R. Solvent Effect in the Thermal Decomposition Reaction of trans-3,3-Dimethyl-5,6-tetramethylene-1,2,4-trioxacyclohexane. J. Org. Chem., 1999, 64, 8457-8460. 
7. Morales, G.; Eyler G.N.; Cerna, J.R.; Cañizo, A.I. Use of Cyclic Di- and Triperoxides as Initiators of Styrene Polymerization at High Temperature with a View to Their Use in Industrial Applications. Molecules 2000, 5, 549-550.

8. Vennerstrom, J.L.; Fu, H.N.; Ellis, W.Y.; Ager, A.L. Jr.; Wood, J.K.; Andersen, S.L.; Gerena, L.; Milhous, W.K. Dispiro-1,2,4,5-tetraoxanes: a new class of antimalarial peroxides J. Medical Chem. 1992, 35, 3023-3027.

9. Kim, H.S.; Shibata, Y.; Wataya, Y.; Tsuchiya, K.; Masuyama, A.; Nojima, M. Synthesis and Antimalarial Activity of Cyclic Peroxides, 1,2,4,5,7-Pentoxocanes and 1,2,4,5-Tetroxanes. J. Med. Chem. 1999, 42, 2604-2609.

10. McCullogh, K.; Nonami, Y.; Masuyama, A.; Nojima, M.; Kim, HS; Wataya, Y. Synthesis, crystal structure and antimalarial activity of novel 1,2,5,6-tetraoxacycloalkanes from 2,3-dihydroperoxy2-phenylnorbornane. Tetrahedrom Lett. 1999, 40, 9151-9155.

11. Rogers, D.W. Computational Chemistry Using the PC, Third Edition, Wiley: New York, 2003.

12. Dewar, M.J.S.; Zoebisch, E.G.; Healy, E.F.; Stewart, J.J.P. AM1: A New General Purpose Quantum Mechanical Model. J. Am. Chem. Soc. 1985, 107, 3902-3909.

13. Stewart, J.J.P. Semiempirical Molecular Orbital Methods, in Reviews in Computational Chemistry, Vol. 1, K.B. Lipkpwitz, D.B. Boyd, Editors, VCH: New York, 1990, 45-81.

14. Stewart, J.J.P. Optimization of parameters for semiempirical methods I. Method. J. Comput. Chem. 1989, 10, 209-220.

15. Stewart, J.J.P. Optimization of parameters for semiempirical methods II. Applications. J. Comput. Chem. 1989, 10, 221-264.

16. Höltje, H.D.; Sippl, W.; Rognan, D.; Folkers, G. Molecular Modeling. Basic Principles and Applications, Second Edition, Wiley: New York, 2003, 23.

17. Story, P.R.; Lee, B.; Bishop, C.E.; Denson, D.D.; Busch, P. Macrocyclic Synthesis. II. Cyclohexanone Peroxides. J. Org. Chem. 1970, 35, 3059-3062.

18. Hubbart, W.N.; Scott, D.W.; Waddington G. In Experimental Thermochemistry; Rossini, F.D. Ed. Interscience: New York, 1956, 75-127.

19. Cox, J.D.; Wagman, D.D.; Medvedev, V.A., Eds.; CODATA Key Values for Thermodynamics; Hemisphere: New York, 1989.

20. Wieser, M.E. Atomic Weights of The Elements 2005 (IUPAC Technical Report). Pure Appl. Chem. 2006, 78(11), 2051-2066.

21. Frisch, M.J.; Trucks, G.W.; Schlegel, H.B.; Gill, P.M.W.; Johnson, B.G.; Robb, A.; Cheeseman, J.R.; Keith, T.A.; Petersson, G.A.; Montgomery, J.A.; Kaghavachari, K.; Al-Laham, M.A.; Kakrewski, V.G.; Ortiz, J.V.; Foresman, J.B.; Cioslowski, J.; Stefanov, B.B.; Nanayakkara, A.; Challacombe, M.; Peng, C.Y.; Ayala, P.Y.; Chen, W.; Wong, M.W.; Andrés, J.L.; Replogle, E.S.; Gomperts, R.; Martin, R.L.; Fox, D.J.; Binkley, J.S.; DeFrees, D.J.; Baker, J.; Stewart, J.P.; HeadGordon, M.; González, C.; Pople, J. A. Gaussian 94, rev D3, SGI; Gaussian, Inc:, Pittsburgh, PA., 1995.

(C) 2007 by MDPI (http://www.mdpi.org). Reproduction is permitted for noncommercial purposes. 